\title{
Adipositas und chronische Inflammation bei phlebologischen und lymphologischen Erkrankungen
}

\section{G. Faerber}

Zentrum für Gefäßmedizin, Hamburg

\section{Schlüsselwörter}

Adipositas-assoziierte funktionelle Veneninsuffizienz, Adipositas-assoziiertes Lymphödem, viszerale Adipositas, chronische Inflammation, Insulinresistenz

\section{Zusammenfassung}

Die Prävalenz der Adipositas ist in den letzten 15 Jahren weiter stark angestiegen. Dabei fällt besonders die deutliche Zunahme der morbiden Adipositas auf, die wiederum bei den Älteren besonders ausgeprägt ist. Da mit dem Alter auch venöse Thromboembolien, chronisch venöse Insuffizienz und sekundäre Lymphödeme zunehmen, steigt die Zahl der Patienten mit venösen oder lymphatischen Erkrankungen, die gleichzeitig schwer adipös und häufig multimorbide sind, überproportional an. Die Adipositas, vor allem die viszerale, verschlechtert alle Ödemerkrankungen, erhöht das Risiko für thromboembolische Erkrankungen und postUrsache sein für die Adipositas-assoziierte funktionelle Veneninsuffizienz ohne Nachweis von Obstruktion oder Reflux. Das Adipositasassoziierte Lymphödem stellt inzwischen den größten Anteil unter den sekundären Lymphödemen. Mehr als 50 Prozent der Lipödempatientinnen sind adipös, die bei innen im Verlauf zu beobachtenden sekundären Lymphödeme in der Regel Folge der Adipositas, nicht des Lipödems. Die Symptomatik wird bei allen Krankheitsbildern durch Gewichtsreduktion gebessert. Neben mechanischen Faktoren wie der Erhöhung des intraabdominalen und intertrigithrombotisches Syndrom und kann alleinige

nösen Drucks, der wiederum zu einer venösen Drucksteigerung in den Beingefäßen führt, sind es vor allem die durch die Zunahme des viszeralen Fettgewebes verursachten metabolischen, chronisch inflammatorischen und prothrombotischen Prozesse, die für diese Zusammenhänge verantwortlich sind, erkennbar an niedrigen Spiegeln von Adiponektin und hohen von Leptin, Insulin, intaktem Proinsulin, PAI-1 sowie proinflammatorischen Zytokinen (II-6, II-8, TNF- $\alpha$ ). Therapeutische Maßnahmen müssen also in erster Linie auf die Reduktion der viszeralen Adipositas und damit der Hyperinsulinämie bzw. der Insulinresistenz sowie auf die Bekämpfung der chronischen Entzündung abzielen.

\section{Keywords}

Obesity-associated functional venous insufficiency, obesity-associated lymphoedema, visceral obesity, chronic low-grade inflammation, insulin resistance

\section{Summary}

The prevalence of obesity has continued to rise considerably during the last 15 years. There is a striking increase of cases with morbid obesity (BMI over $40 \mathrm{Kg} / \mathrm{m}^{2}$ ), especially among the elderly. Since venous thromboembolic events, chronic venous insufficiency and secondary lymphoedema also increase with age, the number of patients who suffer from these conditions and, at the same time, are obese and often multimorbid, rises disproportionately.

Korrespondenzadresse

Dr. med. Gabriele Faerber

Zentrum für Gefäßmedizin

Paul-Dessau-Str. 3e

22761 Hamburg

Tel. 00494046003924

info@gefaesszentrum.de
Obesity and chronic inflammation in phlebological and lymphatic diseases

Phlebologie 2018; 47: 55-65

https://doi.org/10.12687/phleb2413-2-2018

Eingereicht: 08. Februar 2018

Angenommen: 12. Februar 2018

English version available at: www.phlebologieonline.de
Obesity, especially if it is visceral, causes all sorts of oedema to deteriorate, increases the risk of thromboembolic events and postthrombotic syndrome and can be the sole cause of the so called obesity-associated dependency-syndrome, or rather the obesity-associated functional venous insufficiency without obstruction or reflux, as it ought to be called, with its skin lesions characteristic of CEAP stages C4 to C6. Among the various causes of secondary lymphoedema obesity is by now the most common. Of patients suffering from lipoedema more than 50 percent are obese, with the secondary lymphoedema often to be seen in those cases being the direct consequence of obesity, not the lipoedema itself. In all the conditions mentioned above symptoms can be ameliorated by weight loss. Aside from mechanical factors like intraabdominal and intertriginous pressure which in turn raise the intravenous pressure in the legs, it is foremost the metabolic, proinflammatory and procoagulatory effects of the augmented visceral fat tissue which can explain the correlation between obesity and thrombosis, oedema and, probably, the skin changes, too. These effects can be identified by low levels of adiponectin, which has antiinflammatory and vasoprotective qualities, and high levels of leptin, characteristic of leptin resistance, inflammation and insulin resistance, insulin and intact proinsulin (precursor of insulin, indicating $\beta$-cell insufficiency). Plasminogen Activator Inhibitor-1 (PAl-1), preventing fibrinolysis, and proinflammatory cytokines like Interleukin-6 (II-6) , Interleukin-8 (II-8) and Tumour Necrosis Factor- $\alpha$ (TNF- $\alpha$ ) are also found to be raised. In addition to treating the acute or chronic symptoms by anticoagulation, compression, manual lymphdrainage and wound care, therapeutic measures must endeavour to sustainably reduce visceral fat tissue, and thus hyperinsulinaemia, insulin resistance and inflammation. 


\section{Einleitung}

Der normalgewichtige Mann ist in Deutschland bereits ab einem Alter von 30 bis 35 Jahren in der Minderheit, bei Frauen dominieren erst ab 55 Jahren die Übergewichtigen.

Am Ende ihres Berufslebens sind 74,2\% der Männer und 56,3\% der Frauen übergewichtig. Während die Zahl der Übergewichtigen seit einigen Jahren stagniert, stieg der Anteil der Adipösen von 12\% im Jahr 2000 und 15\% 2009 auf 23,6\% im Jahr 2015. Insbesondere bei den über 65-Jährigen hat der Anteil der Personen mit morbider Adipositas (BMI $\geq 40)$ in der Zeit von 1999 bis 2013 bei den Männern um 300\% und bei den Frauen um 175\% zugenommen (1). Da auch die Prävalenz von thromboembolischen Ereignissen, chronisch venöser Insuffizienz (2) und sekundären Lymphödemen mit dem Alter zunimmt, steigt die Zahl der Patienten mit diesen Krankheitsbildern, die gleichzeitig schwer adipös sind, stetig an. Begünstigt wird die Entwicklung von Übergewicht und Adipositas durch eine familiäre Disposition bzw. genetische Ursachen $(3,4)$, Medikamente, endokrinologische und psychische Erkrankungen, sowie einen niedrigen Sozial- und Bildungsstatus (5). Vor allem wird die rasante Ausbreitung der Adipositasepidemie aber verursacht durch den heutigen Lebensstil, der geprägt ist von der ständigen Verfügbarkeit von meist ungesundem Essen, häufigem „Snacken“ (6), Bewegungsmangel durch sitzende Tätigkeiten in geschlossenen Räumen, chronischen Stress (7) und Schlafmangel (8-10).

\section{Adipositas-assoziierte Erkrankungen der Venen und Lymphgefäße}

Adipositas verschlechtert alle bestehenden Ödemerkrankungen bzw. kann eine solche erst verursachen (11). Sie erhöht das Risiko für thromboembolische Erkrankungen und postthrombotisches Syndrom (PTS), sowie den Schweregrad von chronisch venöser Insuffizienz (CVI), postthrombotischem Syndrom (PTS) und Ulcus cruris (12).

\section{Thromboembolie und} postthrombotisches Syndrom

Abdollahi et al. fanden 2008 in den Niederlanden bei 454 konsekutiven Patienten mit einer ersten Thrombose eine Verdoppelung des Thromboserisikos bei einem BMI ab $30 \mathrm{~kg} / \mathrm{m}^{2}$ (CI95: 1.5 vs. 3.4), sowie eine Erhöhung der Faktoren VIII und IX. Das relative Risiko war für beide Geschlechter und alle Altersgruppen ähnlich, absolut war der Effekt bei den Älteren am größten (13). Eine prospektive Kohortenstudie von Ageno et al. an 83 konsekutiven Thrombosepatienten zeigte, dass bereits ein BMI > $28 \mathrm{~kg} / \mathrm{m}^{2}$ ein Prädiktor für die frühzeitige Entwicklung eines postthrombotischen Syndroms ist. Nach 12 Monaten wurde bei 24,1 Prozent ein PTS festgestellt; in dieser Gruppe war der mittlere BMI signifikant höher (29,6 vs. $\left.27,2 \mathrm{~kg} / \mathrm{m}^{2}, \mathrm{p}=0.022\right)$. Die Autoren kamen zu dem Schluss, dass Thrombosepatienten eine Gewichtszunahme unbedingt vermeiden sollten und eine Reduktion möglicherweise dazu beitragen könnte, ein PTS zu vermeiden (14).

\section{CVI und Ulcus cruris}

Der Einfluss des Körpergewichts auf die Schwere der CVI wird in der Literatur kontrovers diskutiert, vor allem deshalb, weil mit dem Alter sowohl CVI als auch BMI zunehmen (2). Chiesa et al. beschrieben in einer großen epidemiologischen Studie mit über 16000 Probanden einen Zusammenhang zwischen BMI, sichtbaren Zeichen der CVI und Zunahme des venösen Refluxes (15). Dagegen fanden Padberg et al 2003 in einer retrospektiven Studie (20 Männer, 39 Beine, CEAP C4 bis C6, BMI $\geq 40 \mathrm{~kg} / \mathrm{m}^{2}$ ) bei zwei Drittel der Patienten trotz typischer Hautveränderungen (Hyperpigmentierungen, Dermatoliposklerose bis hin zum hydrostatischen Ulcus cruris) bei der Duplexuntersuchung keinen venösen Reflux, hinsichtlich des klinischen Befundes (VCSS, venous clinical severity score) gab es zwischen den Patienten mit oder ohne Reflux keinen Unterschied (16). In einer Querschnittstudie aus Serbien beschrieben die Autoren 2013 ebenfalls eine von Alter, Geschlecht und anderen Risikofaktoren unabhängige starke Korrelation zwischen Adipositas und CEAP-C-Stadien, aber nicht zwischen Adipositas und venösem Reflux (17). Dass adipöse Patienten CVI-typische Hautveränderungen auch ohne venösen Reflux haben können, zeigten auch Danielsson et al. durch Duplexultraschalluntersuchungen an über 400 Beinen (18). Sie fanden eine starke Korrelation zwischen BMI und der Schwere der klinischen Symptomatik und beschrieben Übergewicht als einen unabhängigen Risikofaktor für CVI-typische Hautveränderungen. Über 50\% der Adipösen hatten Ödeme und ein florides oder abgeheiltes Ulkus. Auch Obermayer et al. beschrieben in einer Ulkusstudie einen Anteil von 46\% Adipösen und 35\% Übergewichtigen (19). Insgesamt wird in Abhängigkeit vom Grad der Adipositas ein Anteil so genannter venöser hydrostatischer Ulzera ohne Reflux zwischen 20 und über 60\% angegeben (16, 20). Nach Gewichtsreduktion bessern sich die Hautveränderungen $(21,22)$.

Zusammengefasst werden die im Rahmen einer Adipositas auftretenden CVI-typischen Symptome als sogenanntes „Adipositas-assoziiertes Dependency-Syndrom“ in Analogie zum durch Immobilität verursachten Dependency-Syndrom bei Gelähmten $(23,24)$. Garzon und Obermayer gelang der Nachweis, dass der intertriginöse Druck in der Leiste bereits ab einem BMI von $25 \mathrm{~kg} / \mathrm{m}^{2}$ mit dem Beinvenendruck korreliert und dass es bei Adipositas neben der dadurch verursachten Obstruktion der Beinvenen durch das auf der Leiste lastende Gewicht zu einer völligen Inaktivierung der Wadenmuskelpumpe im Sitzen kommt, sodass das an sich gesunde Venensystems nicht entlastet werden kann und der venöse Druck steigt. Die Autoren sehen darin eine mögliche Erklärung für die Entstehung der hydrostatischen Ulzera (23). Da höchstwahrscheinlich weitere, vor allem metabolische Zusammenhänge zur Pathogenese beitragen, wird das Krankheitsbild besser als sekundäre funktionelle Veneninsuffizienz ohne Nachweis von Reflux oder Obstruktion beschrieben (11).

\section{Lymphödem und Lipödem}

Im Vergleich zur Normalbevölkerung mit einem Adipositasanteil von gut 20\% sind Patienten mit lymphologischen Erkrankungen weit häufiger übergewichtig oder 
adipös (siehe dazu auch Bertsch, Tobias in dieser Ausgabe). Reich-Schupke fand im Rahmen einer Studie bei 72 Patienten der lymphologischen Sprechstunde am Venenzentrum der Ruhr-Universität Bochum einen mittleren BMI von $38 \mathrm{~kg} / \mathrm{m}^{2}$, wobei der Adipositasanteil in Abhängigkeit von der lymphologischen Diagnose stark differierte (25). Flaggl et al. fanden in einem lymphologischen Kollektiv 24\% Patienten mit Normgewicht (26). Adipositas führt zur Verschlechterung primärer Lymphödeme (27), sekundäre postoperative Lymphödeme treten bei Adipösen häufiger, früher und schwerer auf (28). Vor allem aber ist die morbide Adipositas (BMI über $40 \mathrm{~kg} / \mathrm{m}^{2}$ ) inzwischen die häufigste Ursache für ein sekundäres Lymphödem, das als Adipositas-assoziiertes Lymphödem eine eigene Entität bildet (29). Typischerweise entwickelt es sich in der zweiten Lebenshälfte parallel zur Gewichtsentwicklung vor allem an den Oberschenkeln, in der Genitalregion und abdominal im Bereich der Fettschürzen, während die Fibrosierung an den Unterschenkeln wenig ausgeprägt und das Stemmer-Zeichen oft nur schwach nachweisbar sein kann (29). Häufig ist das Adipositas-assoziierte Lymphödem mit den für die sekundäre venöse Insuffizienz typischen Hautveränderungen kombiniert $($ Abb. 1).

Für das Lipödem geben Schmeller et al. in ihrem Kollektiv den Anteil normgewichtiger Patientinnen mit 29\% an (30). Tatsächlich dürfte der Anteil adipöser Lipödempatientinnen bei weit über $50 \%$ liegen (31). Das sekundäre Lymphödem, das sich bei diesen Patientinnen im Verlauf häufig entwickelt, ist dann Folge der Adipositas, nicht des Lipödems. Zwischen der asymptomatischen Lipohypertrophie und dem symptomatischen, schmerzhaften Lipödem scheint es in beide Richtungen Übergänge zu geben, meist in Phasen von Gewichtsoder Hormonveränderungen $(32,33)$. Die Adipositas verschlechtert durch die zusätzlichen Fettmassen an den Oberschenkeln Achsenfehlstellung, Gangbild und Mobilität, wodurch das Gewicht weiter ansteigt.

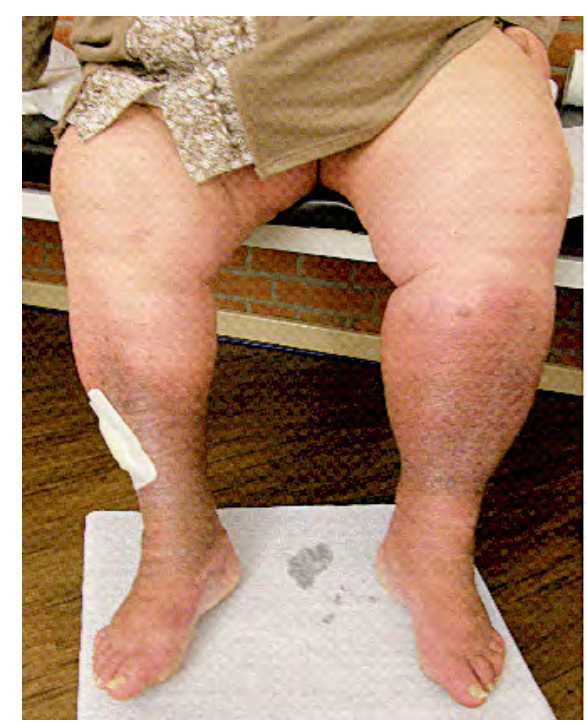

Abb. 1 Adipositas-assoziiertes Lymphödem mit sekundärer funktioneller Veneninsuffizienz. BMI $61 \mathrm{~kg} / \mathrm{m}^{2}$ (162cm, BMI 61. WHtR 0,88). Hyperpigmentation, Dermatoliposklerose, Ulcus cruris re 0,5x0,5 cm, Lymphorrhoe; Diabetes mell. Typ II, Art. Hypertonus.

\section{Der Einfluss des viszeralen Fettgewebes auf Hyperkoagubilität, chronische Inflammation und Insulinresistenz}

Für die Zusammenhänge zwischen der Adipositas und den oben beschriebenen Krankheitsbildern gibt es mechanische Erklärungsansätze (Druckerhöhung intraabdominal, intertriginös und konsekutiv venös) und solche, die die Rolle der chronischen Inflammation und der mit der Adipositas verbundenen metabolischen Veränderungen in den Vordergrund stellen. Sie schließen sich nicht aus sondern ergänzen sich.

\section{Viszerale Adipositas, Thrombose und sekundäre venöse Insuffizienz}

Willenberg und Kollegen fanden bei Adipösen einen vergrößerten Durchmesser der V. femoralis und eine Verschlechterung der venösen Flussparameter. Sie sahen hierin eine Bestätigung dafür, dass das abdominale Fettgewebe über die Erhöhung des intraabdominalen Drucks auf mechanische Weise das Risiko für venöse Thromboem- bolien und CVI erhöhen könnte (34). Darvall et al. beschrieben hingegen in einer Übersichtsarbeit, dass insbesondere die viszerale Adipositas mit einer erhöhten Inzidenz und Prävalenz von arteriellen und venösen Thromboembolien assoziiert ist (35). Das viszerale Fettgewebe ist nicht nur ein Energiespeicher sondern Produktionsstätte zahlreicher Hormone und Zytokine, die den Glukose- und Lipidstoffwechsel und die Blutgerinnung beeinflussen $(\checkmark$ Tab. 1). Die Sekretion von Leptin wird durch TNF- $\alpha$ und Hyperinsulinämie gesteigert. Leptin fördert die Thrombozytenaggregation, steigert über die Aktivierung der IL-6 Rezeptoren die Synthese von CRP und wirkt so proinflammatorisch. Adiponektin ist bei Insulinresistenz und Adipositas erniedrigt. Hohe Spiegel wirken antiinflammatorisch: CRP, TNF- $\alpha$, IL-6, IL-8 und Plasminogen-Aktivator-Inhibitor-1 (PAI-1) sinken. Steigende Spiegel gehen mit sinkender Insulinresistenz und der Verbesserung der kardiovaskulären Risikofaktoren einher.

Insgesamt erhöht die abdominale Adipositas das Thromboserisiko durch die gesteigerte Aktivität der Koagulations- und eine verringerte der fibrinolytischen Kaskade, vermehrte Inflammationsprozesse, erhöhten oxidativen Stress und endotheliale Dysfunktion. Hinzu kommen Störungen des Lipidstoffwechsels und der Glukosetoleranz im Rahmen des metabolischen Syndroms (Insulinresistenz, erhöhte Triglyzeride, niedriges HDL), die ebenfalls proinflammatorisch wirken und die endotheliale Dysfunktion verstärken. Durch Gewichtsreduktion können diese thrombogenen Risiskofaktoren ausnahmslos gebessert werden (35). Auch Ageno et al. kamen in ihrer Metaanalyse zu dem Ergebnis, dass das viszerale Fettgewebe als endokrines Organ ursächlich ist für die chronische Inflammation und damit für einen thrombogenen $\mathrm{Zu}$ stand, der das Risiko für venöse Thromboembolien erhöht (36). Die chronische Inflammation steigert Fibrinogen, Gewebefaktor (Tissue factor, Faktor III) und Faktor VII und aktiviert so die Gerinnungskaskade. Bei Patienten mit viszeraler Adipositas finden sich außerdem häufig erhöhte PAI-1-Spiegel und niedrige Werte des gewebespezifischen Plasminogenaktivators (t-PA), der aus den Endothelzellen der Ge- 
Tab. 1 Metabolische und inflammatorische Marker, Zytokine

\begin{tabular}{|c|c|}
\hline Marker, Bildungsstätte & \\
\hline $\begin{array}{l}\text { Adiponektin } \\
\text { Peptidhormon, Fettzellen; } \\
\text { antiatherogen, antiinflam- } \\
\text { matorisch }\end{array}$ & $\begin{array}{l}\text { Niedrige Werte assoziiert mit: } \\
\text { viszeraler Adipositas (unterdrückt die Sekretion) } \\
\text { Insulinresistenz und Hyperinsulinämie } \\
\text { Dyslipidämie (hohe Triglyzeride, niedriges HDL) } \\
\text { Inflammation } \\
\text { Stress } \\
\text { erhöhtem Risiko für Diabetes mell. Typ II, KHK }\end{array}$ \\
\hline $\begin{array}{l}\text { Intaktes Proinsulin } \\
\text { Vorläufer von Insulin } \beta \text {-Zel- } \\
\text { len des Pankreas }\end{array}$ & $\begin{array}{l}\text { Erhöhte Werte assoziiert mit: } \\
\text { fortgeschrittener Dysfunktion der } \beta \text {-Zellen } \\
\text { Prädiabetes } \\
\text { erhöhtem kardiovaskulärem Risiko (stimuliert PAI-I, blockiert Fibrinolyse) } \\
\text { weiterer Gewichtszunahme }\end{array}$ \\
\hline $\begin{array}{l}\text { Leptin } \\
\text { Proteohormon, Adipozyten } \\
\text { Regulation des Körperge- } \\
\text { wichts }\end{array}$ & $\begin{array}{l}\text { Hohe Werte assoziiert mit: } \\
\text { Leptinresistenz } \\
\text { viszeraler Adipositas } \\
\text { Hyperinsulinämie, } \beta \text {-Zell-Dysfunktion, hohen Triglyzeride, niedrigem HDL } \\
\text { Inflammation }\end{array}$ \\
\hline $\begin{array}{l}\text { hs-CRP } \\
\text { Akut-Phase-Protein } \\
\text { Leber, Gefäßmuskelzellen }\end{array}$ & $\begin{array}{l}\text { Hohe Werte assoziiert mit: } \\
\text { chronischer Inflammtion } \\
\text { Insulinresistenz, erhöhtem Diabetes-II-Risiko } \\
\text { Hypertension,metabolischem Syndrom } \\
\text { Erhöhtem Risiko für vaskuläre Ereignisse }\end{array}$ \\
\hline $\begin{array}{l}\text { Plasminogen-Aktivator- } \\
\text { Inhibitor-1 } \\
\text { (PAl-1) } \\
\text { v.a. viszerales Fettgewebe }\end{array}$ & $\begin{array}{l}\text { Hohe Werte assoziiert mit: } \\
\text { viszeraler Adipositas } \\
\text { Inflammation und oxidativem Stress }\end{array}$ \\
\hline Hemmung der Fibrinolyse & $\begin{array}{l}\text { Erhöhtem Risiko für thrombembolische Ereignisse, Atherosklerose } \\
\text { Insulinresistenz, metabolischem Syndrom, Diab.mell. Typ II }\end{array}$ \\
\hline $\begin{array}{l}\text { Inflammatorische Zytokine: } \\
\text { IL-6, IL-8, TNF- } \alpha \\
\text { Viszerales Fettgewebe } \\
\text { Stimulation von Entzün- } \\
\text { dungsprozessen }\end{array}$ & $\begin{array}{l}\text { Hohe Werte assoziiert mit: } \\
\text { chronischer Inflammation } \\
\text { viszeraler Adipositas } \\
\text { Insulinresistenz, Diab.mell. Typ II } \\
\text { vaskulären Ereignissen }\end{array}$ \\
\hline
\end{tabular}

fäßwand freigesetzt wird und als körpereigener Aktivator der Fibrinolyse wirkt, indem er Plasminogen direkt in Plasmin umwandelt. Der PAI-1-Spiegel korreliert positiv mit dem BMI und dem Plasmainsulinund Triglyceridspiegel. Wird der Insulinspiegel durch Fasten oder Metformin gesenkt, sinkt auch PAI-1 (37), was vermuten lässt, dass die Hyperinsulinämie die hepatische Synthese von PAI-1 steigert und so zu einem hypofibrinolytischen Zustand beiträgt (38).

Vieles deutet darauf hin, dass auch für die Hautveränderungen im Rahmen der sekundären venösen Insuffizienz bis zum hydrostatischen Ulkus neben den oben beschriebenen mechanischen Faktoren die durch die viszerale Adipositas verursachten chronisch inflammatorischen und prothrombotischen Prozesse eine Rolle spielen, da diese unter anderem Kapillarpermeabilität, Extravasation und konsekutiv die lymphpflichtige Last erhöhen (24).

\section{Adipositas, chronische Inflammati- on und Lymphödem}

Bei Adipositas und metabolischem Syndrom sind erhöhte Level proinflammatorischer Zytokine nicht nur systemisch sondern auch im Fettgewebe, in der Leber und in der Skelettmuskulatur nachweisbar. Eine Vielzahl von Studien konnte zeigen, dass ein Anstieg proinflammatorischer Zytokine, wie TNF- $\alpha$, IL- 6 und MCP-1 (macrophage chemotactic protein 1) zu Insulinre- sistenz im Fettgewebe, gesteigerter Lipolyse und Leberverfettung führt (39). Karaman et al. zeigten im Mausmodell, dass der für die Lymphangiogenese wichtige Rezeptor VEGFR-3 und seine Liganden VEGF-C und -D nicht nur eine Rolle in der Fettgewebsentzündung und der Entwicklung des metabolischen Syndroms spielen, sondern auch für die Entwicklung des Adipositasassoziierten Lymphödems von Bedeutung sind $(39,40)$. Dieser Einfluss wird über Makrophagen vermittelt, die neben T-Zellen eine Hauptrolle bei der Adipositas-assoziierten Entzündungsreaktion spielen (41).

Dass die Expansion des Fettgewebes einer verstärkten Neoangiogenese bedarf, ist lange bekannt. Über erhöhte Serumspiegel von VEGF-A, -C und -D wurde in verschiedenen Untersuchungen bei übergewichtigen und adipösen Patienten im Vergleich zu schlanken Personen berichtet (42, 43). Interessanterweise fanden sich hierbei auch sexuelle Unterschiede. VEGF-C und -D sowie Angiopoietin 2 waren bei übergewichtigen Frauen stärker erhöht als bei übergewichtigen Männern.

VEGF-A stimuliert hauptsächlich die Proliferation und Migration von Gefäßendothelzellen. Eine Überexpression von VEGF-A in transgenen Mäusen führte zu einer erhöhten Anzahl und zu größeren Blutgefäßen. Diese Mäuse waren aber auch geschützt vor der Entwicklung einer „highfat-diet" induzierten Adipositas und vor Insulinresistenz (44). Insofern scheinen verstärkte VEGF-A Level eine Immunantwort darzustellen, um der Fettgewebshypoxie zu begegnen und hypoxiebedingte Entzündungsprozesse zu regulieren.

Durch die bei der Adipositas verstärkte Expression von VEGF-C, dem wichtigsten Wachstumsfaktor für die Lymphangiogenese, scheint es jedoch zu einer lymphatischen Dysfunktion zu kommen. Diese Erkenntnis wird unterstützt durch die Beobachtung, dass die Blockade des VEGFR-3 Liganden VEGF-C im Mausmodell zur Reduktion der Ödembildung und zu einer signifikanten Besserung der Insulinsensitivität sowie zu geringerer Steatosis hepatis führt (39).

VEGF-C mRNA ist sowohl bei genetischer als auch diätetisch induzierter Adipositas erhöht im Fettgewebe von Mäusen 


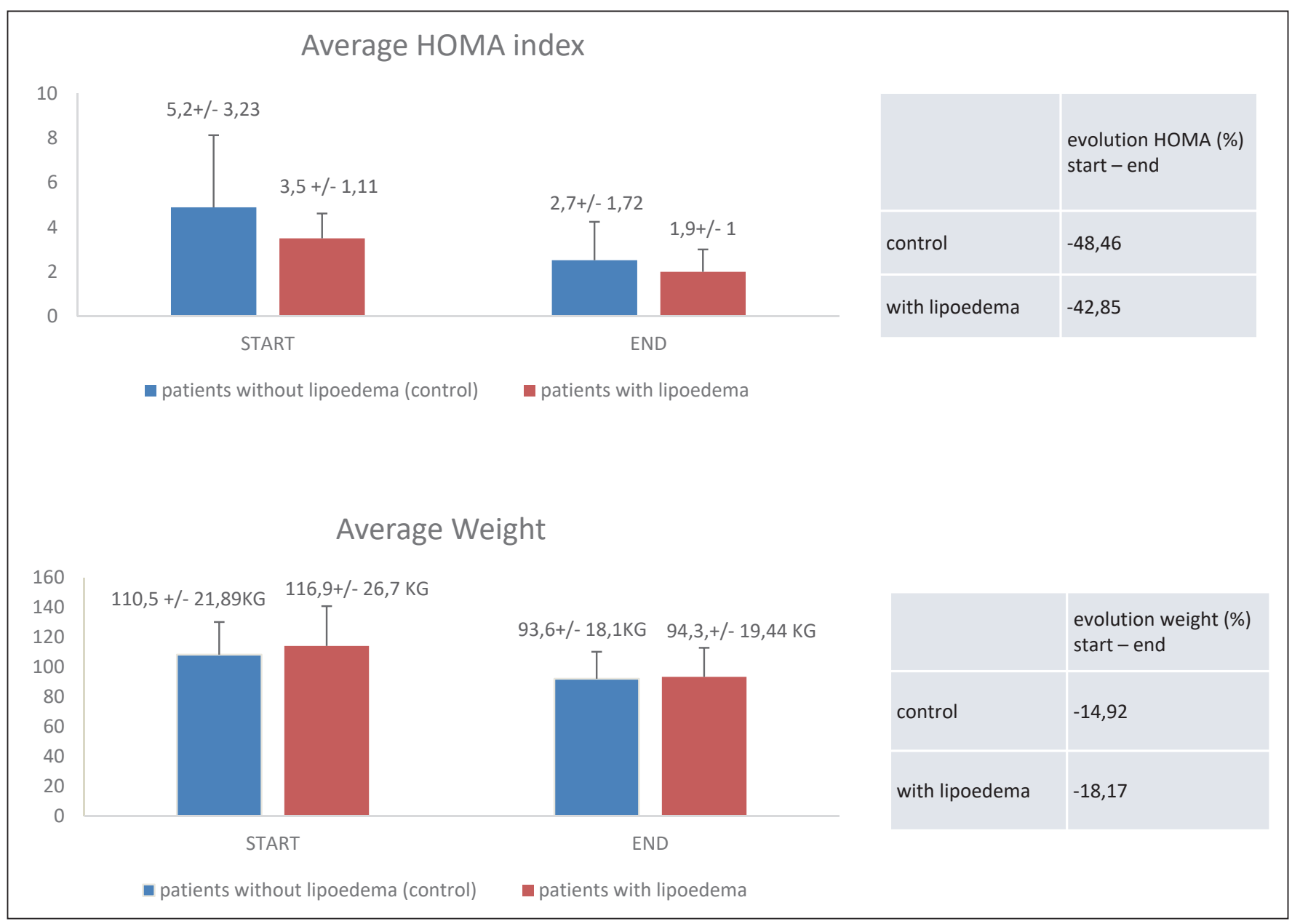

Abb. 2 Durchschnittlicher HOMA-Index und Gewicht vor und nach Ernährungstherapie. Lipödempatientinnen hatten ein höheres Ausgangsgewicht bei niedrigerem HOMA-Index.

nachweisbar, was zu der Vermutung führt, dass das entzündete Fettgewebe selbst eine der Quellen der erhöhten VEGF-C Level ist $(39,40)$. Es kommt bei der Adipositas zu einer verstärkten Einwanderung vom M1 polarisierten Makrophagen ins Fettgewebe. Ein Merkmal dieser M1-Makrophagen ist neben der proinflammatorischen Zytokinfreisetzung die verstärke Expression des VEGFR-3.

Über VEGFR-3 wird zunächst die Lymphangiogenese angeregt. Verschiedene Arbeitsgruppen zeigten jedoch, dass Adipositas zu einem reduzierten Lymphfluss und einer reduzierten Aufnahme der Lymphflüssigkeit in die Lymphknoten führt. Ursächlich dafür scheinen unreife, vermehrt durchlässige („leaky“) Lymphgefäße zu sein $(45,46)$. Zudem kommt es durch Freisetzung von induzierbarer Stickstoffmonoxidsynthase (iNOS) durch Makrophagen zur Dilatation der Lymphgefäße und damit verbunden zur verringerten Kontraktionsintensität. Schließlich ist auch die Kontraktionsfrequenz der Lymphkollektoren reduziert $(45,46)$.

In der Folge resultiert eine Lymphstase. Diese führt langfristig, wie bei anderen sekundären Lymphödemen auch, zumindest im subkutanen Fettgewebe zu einem M2 Makrophagen-Shift und einer TH2 dominierten Entzündungsreaktion, die verantwortlich ist für die weitere lymphödemassoziierte, lokale Fettgewebsneubildung, die Fibrose des umliegenden Gewebes sowie die Sklerose der Lymphgefäße (47). Es entwickelt sich ein Circulus vitiosus.

\section{Adipositas und Lipödem - Inflammation, Insulin, Östradiol}

Auch wenn die Pathogenese des Lipödems immer noch weitgehend unbekannt ist, deutet vieles darauf hin, dass neben hormonellen Faktoren auch hier entzündliche Prozesse eine Rolle spielen. Nicht geklärt ist, ob und in welcher Weise diese primär ursächlich sind oder Folge anderer körperlicher Veränderungen wie Adipositas oder hormoneller Dysbalancen. Dass die Adipositas die Symptomatik bei gesicherter Lipödemdiagnose verschlechtert, ist lange bekannt $(48,49)$. Daneben gibt es aber Verläufe, bei denen sich eine asymptomatische Lipohypertrophie erst im Laufe des Lebens, meist in einer Phase deutlicher Gewichtszunahme, zu einem symptomatischen Lipödem entwickelt. In beiden Fällen kann diese Entwicklung nach Gewichtsredukti- 


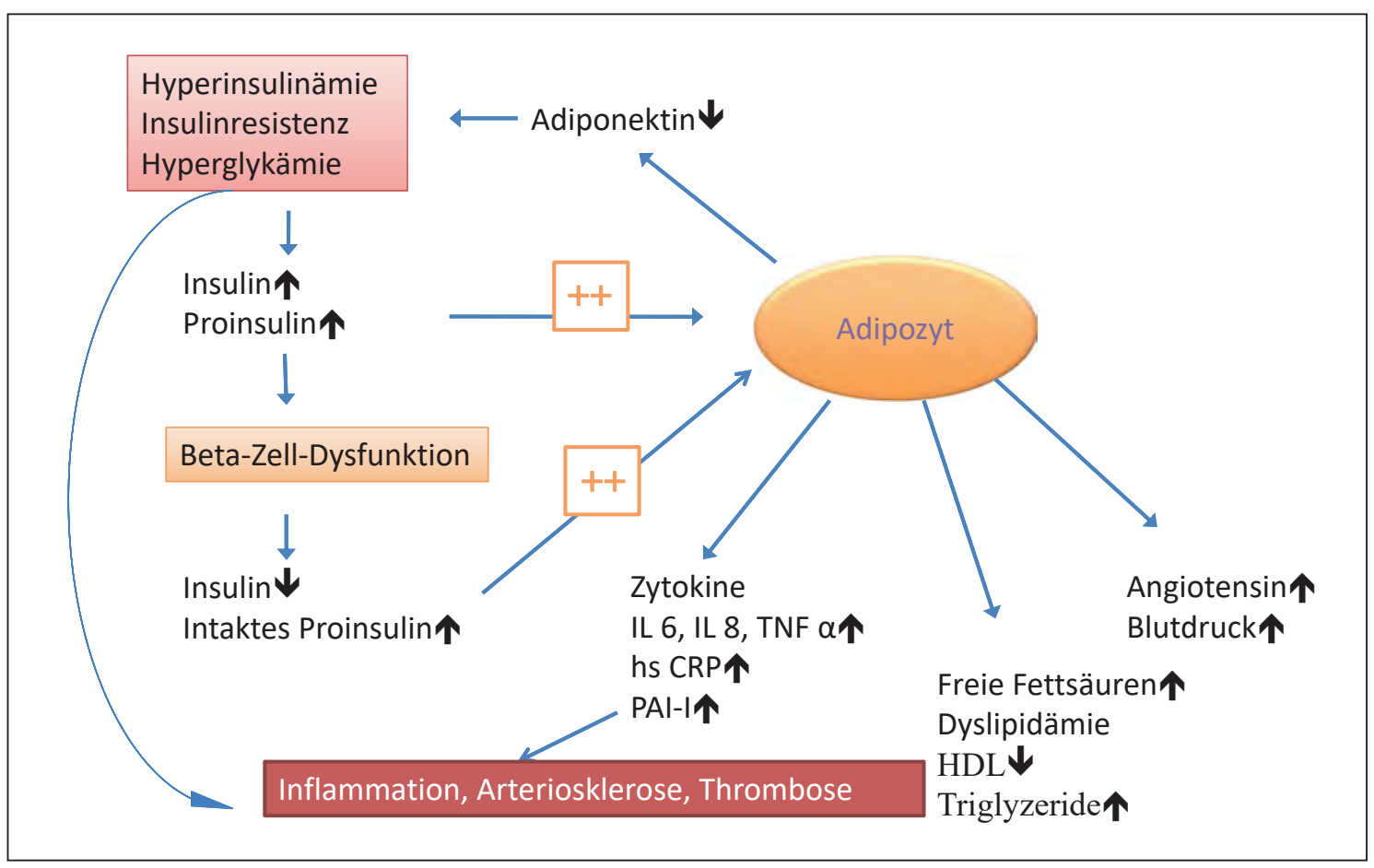

Abb. 3

Zusammenhänge zwischen Adipogenese, Insulinresistenz und Inflammation. Modifiziert (nach Pfützner 2005, modifiziert)

on und Ernährungsumstellung reversibel sein (50). Es ist nachvollziehbar, dass es auch beim Lipödem durch den Circulus vitiosus aus Adipositas und allmählich zunehmender Hyperinsulinämie nicht nur zu einer weiteren Fettgewebszunahme sondern zu den beschriebenen proinflammatorischen und ödemfördernden Effekten des viszeralen Fettgewebes kommt. Bei eigenen Untersuchungen fällt auf, dass die Insulinresistenz in einem Kollektiv adipöser Lipödempatientinnen trotz eines höheren Durchschnittsgewichts weniger ausgeprägt ist als in einem Vergleichskollektiv adipöser Patientinnen ohne Lipödem, wobei sich dieser Unterschied mit zunehmender abdominaler Adipositas verliert $(\triangleright$ Abb. 2) (51).

Insulin stimuliert außerdem direkt die Aromataseaktivität im Fettgewebe und damit die Umwandlung von Androstendion und Testosteron zu Östron und Östradiol (52). Es reduziert zudem das Sexualhormon bindende Globulin (SHBG) und erhöht so das freie Östradiol weiter $(53,54)$. Die Hyperinsulinämie fördert so eine Verschiebung des hormonellen Gleichgewichts zwischen Östradiol und Progesteron zugunsten des Östradiols, das wiederum proinflammatorisch, ödemverstärkend und lipogenetisch wirkt. Die Rolle des Fettgewe- bes als alternative Östradiolbildungsstätte verstärkt also die in der prä- bzw. perimenopausalen Phase physiologischerweise vorliegende Östradioldominanz und trägt so zur Spätmanifestation des Lipödems in dieser Lebensphase bei (51).

\section{Hyperinsulinämie reduzieren, Inflammation bekämpfen}

Die Hyperinsulinämie steigert die Adipogenese, reduziert die Lipolyse und führt so zur Zunahme des viszeralen Fettgewebes und damit zur Bildung von proinflammatorischen und gerinnungsaktivierenden Hormonen und Zytokinen. Die Ödembildung steigt zum einen durch die inflammatorisch erhöhte Kapillarpermeabilität und die gesteigert Retention von Wasser und Natrium, zum anderen durch das insulinvermittelt erhöhte Östradiol.

Therapeutische Maßnahmen müssen also in erster Linie auf die Reduktion der Hyperinsulinämie bzw. die Durchbrechung der Insulinresistenz sowie auf die Bekämpfung der chronischen Entzündung abzielen ( Abb. 3; Tab. 2)
Bei geringer bis mäßiger Insulinresistenz kann die Insulinsensitivität allein durch Veränderungen der Ernährungsgewohnheiten und des Lebensstils verbessert werden.

Vermehrte körperliche Bewegung, vor allem Ausdauertraining im aeroben Belastungsbereich, fördert die Fettverbrennung, dient aber weniger dem Kalorienverbrauch, der meistens überschätzt wird, sondern in erster Linie der Steigerung der Insulinsensitivität der Muskelzellen (55). Bei starkem Übergewicht eignen sich besonders die verschiedenen Bewegungsformen im Wasser (Aqua Cycling, Aqua Jogging etc), um eine Überlastung der Gelenke $\mathrm{zu}$ vermeiden.

In Bezug auf die Ernährung ist sowohl deren Zusammensetzung von Bedeutung, da Blutzucker- und Insulinspitzen im Sinne einer Ernährung mit niedriger glykämischer Last durch Verzicht auf Zucker und raffinierte Kohlenhydrate vermieden werden sollen (56), möglicherweise noch ausschlaggebender ist aber die Reduktion der Mahlzeitenhäufigkeit bzw. der Verzicht auf häufige Zwischenmahlzeiten. Dies bedeutet eine radikale Abkehr von der Empfehlung, viele kleine, vor allem kohlenhydratbetonte Mahlzeiten zu essen. Die Verleihung des Nobelpreises für Medizin an Y. 
Tab. 2

Therapieempfehlungen bei Insulinreistenz und Inflammation

\begin{tabular}{|c|c|c|c|}
\hline Labormarker & $\begin{array}{l}\text { Empfehlungen zur } \\
\text { Lebensführung }\end{array}$ & $\begin{array}{l}\text { Empfehlungen zur } \\
\text { Ernährung }\end{array}$ & $\begin{array}{l}\text { Empfehlungen zur } \\
\text { Nahrungsergänzung }\end{array}$ \\
\hline $\begin{array}{l}\text { Inflammation } \\
\text { Marker: } \\
\text { - hs-CRP } \\
\text { - IL 6, IL8 } \\
\text { - TNF- } \alpha \\
\text { Metabolische } \\
\text { Marker: } \\
\text { - HOMA-IR } \\
\text { - Adiponektin } \\
\text { - Proinsulin }\end{array}$ & $\begin{array}{l}\text { Entzündliche Erkrankungen } \\
\text { ausschließen/behandeln } \\
\text { Insulinsensitivität erhöhen } \\
\text { durch: } \\
\text { - Mehr Bewegung (v.a. } \\
\text { aerob) } \\
\text { - Ausreichend Schlaf } \\
\text { - Stressabbau } \\
\text { - Gewichtsreduktion } \\
\text { - Reduktion der Mahlzeiten- } \\
\text { zahl } \\
\text { - Ggf. Intermittierendes } \\
\text { Fasten } \\
\text { - Ggf. ketogene Ernährung }\end{array}$ & $\begin{array}{l}\text { Vermeidung von: } \\
\text { - Zucker, Fructose, raffinierten } \\
\text { Kohlenhydraten, Transfetten, } \\
\text { - Omega-6-reichen Ölen } \\
\text { - Konservierungsstoffen und Zusatzstoffen, } \\
\text { verarbeiteten Fleischprodukten } \\
\text { - Fleisch aus Intensivmast } \\
\text { - Weizen } \\
\text { - Süßungsmittel reduzieren } \\
\text { Gesunde Fette erhöhen: } \\
\text { - Omega-3-Fettsäuren (Kaltwasserfische) } \\
\text { - Olivenöl, Nüsse und Samen, } \\
\text { - Fleisch und Milchprodukte (vollfett) } \\
\text { bevorzugt von Weidetieren } \\
\text { - Ballaststoffreiche Ernährung, viel frisches } \\
\text { Gemüse, mäßig Obst (vorzugsweise Beeren) }\end{array}$ & $\begin{array}{l}\text { - Fischöl } \\
\text { - Vitamine D, C, B } \\
\text { Bei Bedarf: } \\
\text { - Zink, Magnesium, } \\
\text { Chrom, Selen } \\
\text { - Grünteeextrakt (EGCG) } \\
\text { - Resveratrol } \\
\text { - Kurkumin } \\
\text { - Knoblauch, Ingwer } \\
\text { Rosmarin, Basilikum } \\
\text { - Gymnema silvestre } \\
\text { Hormone: } \\
\text { - Ggf. DHEA (falls } \\
\text { erniedrigt) } \\
\text { - Ggf. Progesteron } \\
\text { (transdermal) }\end{array}$ \\
\hline
\end{tabular}

Ohsumi für seine Forschungen über die Autophagie hat verschiedene Formen des Fastens und deren Auswirkungen auf den Stoffwechsel wieder in den Blickpunkt gerückt. So scheinen eine Ausdehnung der nächtlichen Fastenphase oder das Einlegen von einzelnen Fastentagen (intermittierendes oder periodisches Fasten) nicht nur Gewicht und Insulinsensitivität günstig zu beeinflussen sondern auch antiinflammatorische Effekte zu haben (57-59). Auch bei ausgeprägter Insulinresistenz oder manifestem Diabetes Typ II lassen sich hierdurch und durch starke Reduktion der Ka- lorienzufuhr in $87 \%$ der Patienten bei kurzer bzw. $50 \%$ bei langer Diabetesdauer nach acht Wochen nichtdiabetische Nüchternblutzuckerwerte sowie unabhängig von der Diabetesdauer signifikante Verbesserungen von Blutdruck und Blutlipiden erreichen $(60,61)$. Diese Ergebnisse sind also mit denen nach bariatrischen Operationen vergleichbar, bei denen ebenfalls eine rasche Normalisierung des Stoffwechsels bei Diabetes Typ II erreicht wird, die aber weder bei allen Patienten möglich noch von allen gewünscht und nicht ohne Risiken ist. Abgesehen vom unmittelbaren Operati- onsrisiko gehören hierzu langfristig Fehloder Mangelernährung, Osteoporose, Ösophagitis, Dumping-Syndrom und Blutzuckerschwankungen bei Diabetes, erhöhte Suizid- und Unfallraten im Vergleich $\mathrm{zu}$ Nichtoperierten, erhöhter Drogenkonsum, sowie eine Rate von bis zu 20\% Therapieversager (62-64). Eine langfristige Nachsorge und Betreuung ist sowohl nach Adipositaschirurgie als auch nach Ernährungstherapie zwingend erforderlich, nur dann sind zufriedenstellende Langzeitergebnisse möglich (65).

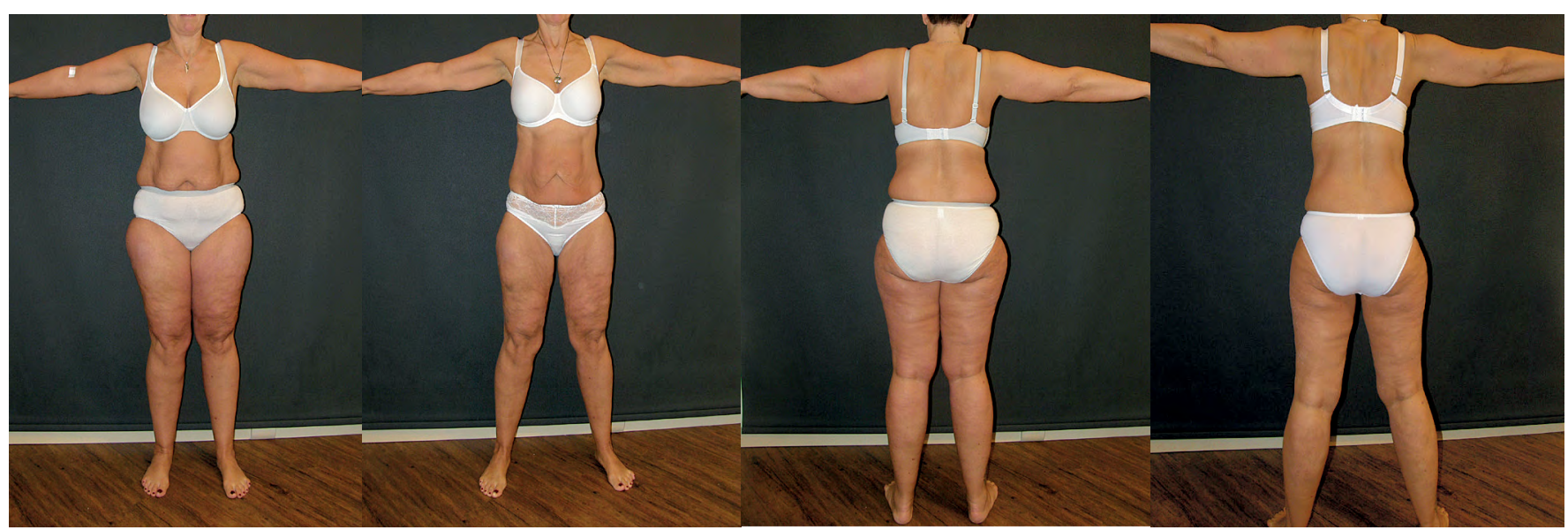

Abb. 4 Fallbeispiel Lipödem: Adipositas Grad I (BMI 31,1), 91,2kg;WHtR 0,55; Lipödem der Arme (Stad I) und Beine (Stad II); Berührungsempfindlichkeit, Spontanschmerzen, 3-4 lbu 400/Tag; frühberentet "wegen ihrer Beine und der Schmerzen"; Rheumatologie und Muskelbiopsie opB; HOMA-IR 1,3;
CRP 2,3; jeweils rechte Abbildung: Ketogene Ernährung, Omega 3 Supplementierung; Gewichtsabnahme 19 kg in 3 Monaten. Keine Beschwerden, keine Schmerzmedikation mehr; treibt wieder Sport 


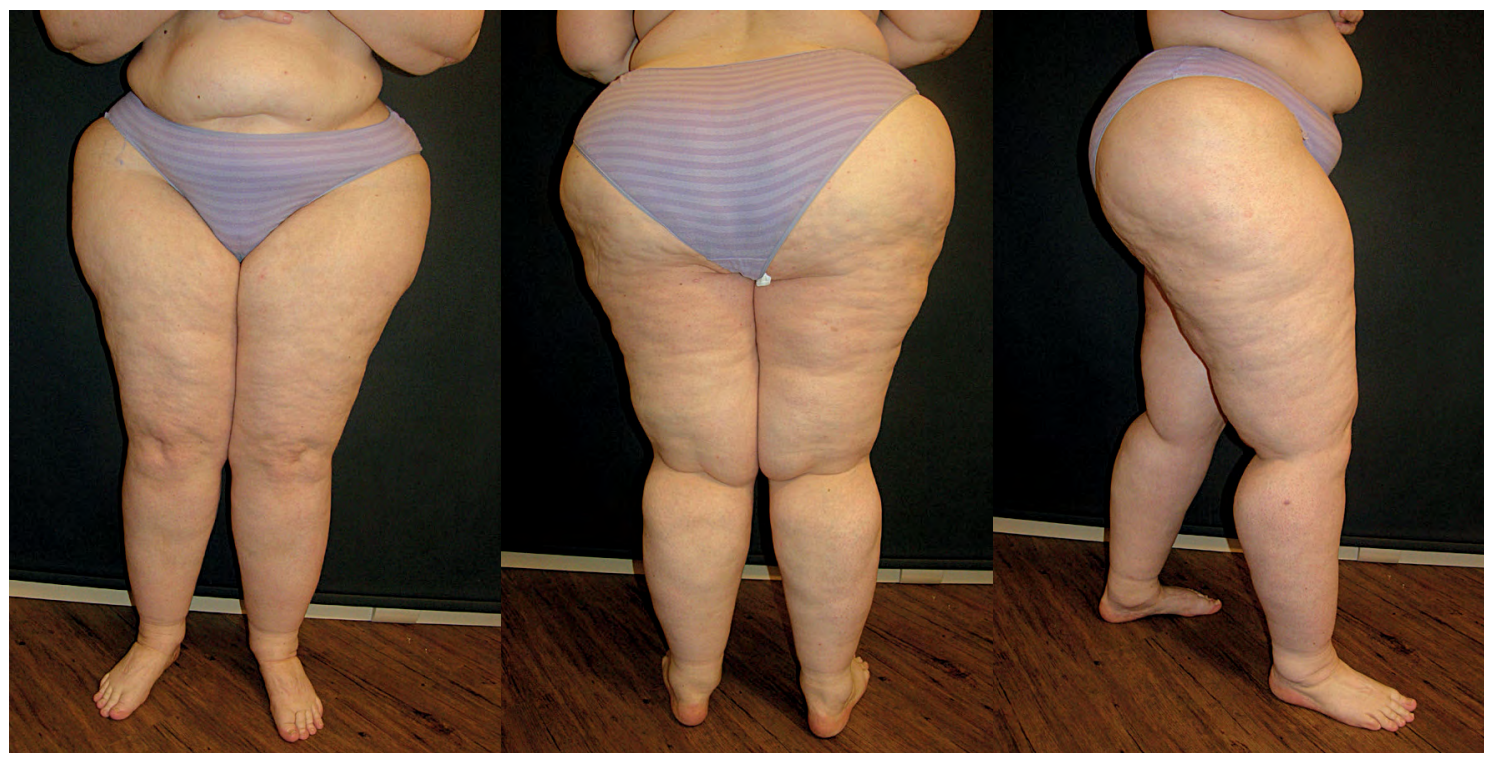

Abb. 5

Fallbeispiel Lipödem: Lipödem Stad II; Gewicht $141 \mathrm{~kg} ; 178$ cm; BMI 44,5; Ketogene proteinreiche Ernährung; Symptombesserung bereits nach 1 Woche (subjektiv und objektiv durch Lymphtherapeuten)
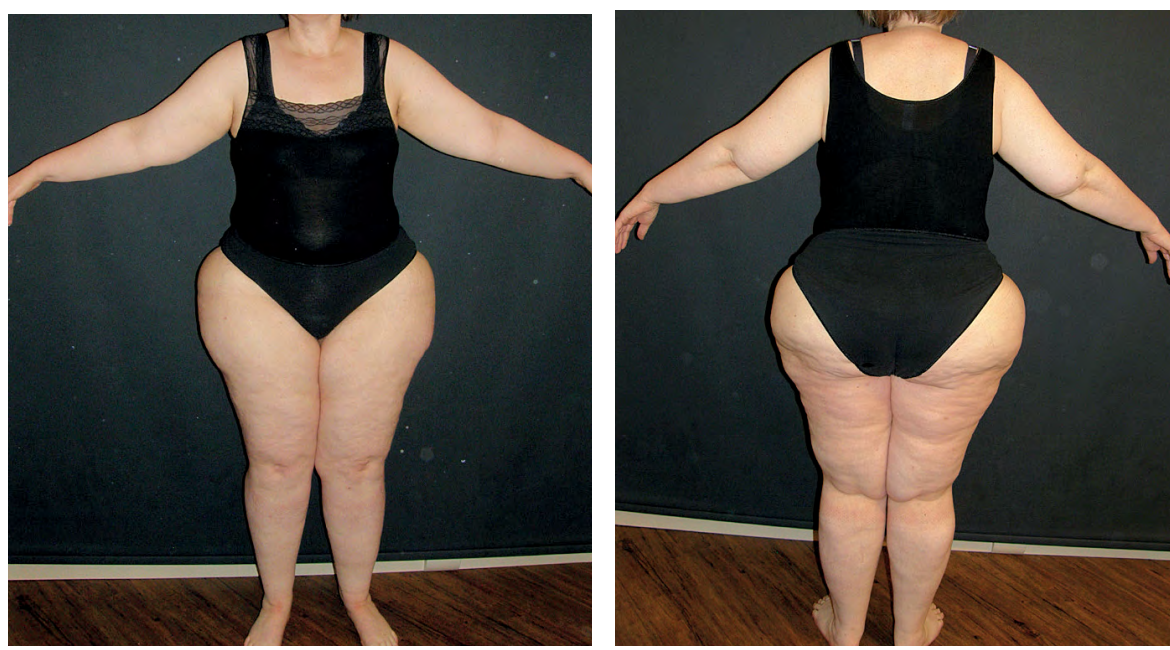

Abb. 6 Fallbeispiel Lipödem: Gewichtsabnahme; 104 kg (-36,5 kg) Umfangsabnahmen von 10-18 $\mathrm{cm}$ : Immer noch massive Lipohypertrophie. Keine Beschwerden, kein Lymphödem mehr.

Für die ketogene Ernährung (very low carb ketogenic diet, VLCKD) belegen bereits zahlreiche Studien eine Reduktion von Entzündungsparametern und kardiovaskulären Risikofaktoren (66-68); bei neurodegenerativen Erkrankungen zeichnen sich ebenfalls günstige Effekte ab $(69,70)$. Die Reduktion der Kohlenhydratzufuhr unter die individuelle Ketoseschwelle normalisert Glucose und Insulin auf niedrigem Niveau. Die Sekretion proinflammatorischer Enzyme (Interleukine 6 und 8, TNF- $\alpha$ ) wird reduziert, Diurese und Natriurese werden gesteigert, die Blutkonzentration von Arachidonsäure und Omega-6-Fettsäuren nimmt ab. Beta-Hydroxybutyrat wirkt direkt antiinflammatorisch durch Blockierung eines Teils des Immunsystems, der an verschiedenen entzündlichen Erkrankungen beteiligt ist (71). Im Gegensatz zur der extrem fettreichen ketogenen Ernährung bei anderen Krankheitsbildern, bei denen eine Gewichtsabnahme unerwünscht ist (Epilepise, Tumorerkrankungen), kann bei Übergewicht durch eine geringe bis mäßige Fettzufuhr ein Kaloriendefizit herbeigeführt werden, da die Bildung der Ketone aus der Lipolyse erfolgt. Dabei ist es sinnvoll, auf die Qualität der Nahrungsfette zu achten: Wünschenswert ist ein möglichst hoher
Anteil antiinflammatorisch wirkender Omega-3-Fettsäuren aus pflanzlichen und marinen Quellen und ein möglichst geringer Anteil proinflammatorischer Omega6-Fettsäuren. Im Gegensatz zu industriellen Transfetten fanden sich für die in Milchprodukten enthaltenen natürlichen Transfette positive Wirkungen auf HDL, Entzündungsmarker und Gefäßgesundheit. Wegen ihres höheren Gehaltes an Omega-3-Fettsäuren und konjugierter Linolsäure sind vollfette Milchprodukte aus Weidehaltung zu empfehlen sind (72).

Auch die zum Schutz der Magermasse und zur Sättigung (73) erforderliche, qualitativ und quantitativ ausreichende Proteinzufuhr kann im Hinblick auf ihre pro- oder antiinflammatorischen Eigenschaften modifiziert werden: Empfohlen wird Fisch, wegen ihres Gehaltes an Omega-3-Fettsäuren besonders fettreiche Kaltwasserfische wie Hering, Makrele und Wildlachs. Fleisch von Tieren aus Weidehaltung (Lamm, Rind) oder Wild enthält mehr Omega-3-Fettsäuren und deutlich weniger Arachidonsäure als Schwein und Pute sowie Fleisch von Tieren aus industrieller Massenmast. Eine Studie mit 37 DiabetesII-Patienten zeigte, dass eine hochnormale Proteinzufuhr den Fettgehalt der Leber, Leberenzyme, Entzündungsparameter und Insulinresistenz reduziert (73). Empfohlen werden 1 bis 1,2 Gramm Protein pro Kilogramm des Normalgewichts, diese Menge reicht in der Regel aus um die Magermasse 
zu schützen (74) und, da das Gehirn zwar die Ketone gut als alternative Energiequelle nutzen kann, aber zu etwa 15 bis $20 \%$ von Glukose abhängig ist, um die dafür notwendige Glukoneogenese zu unterhalten. Erst bei deutlich höherer Proteinzufuhr $(>2 \mathrm{~g} / \mathrm{kg})$ steigt die Insulinsekretion aufgrund der vermehrten Gluconeogenese wieder an. Für die Patienten hat die Ketose den unmittelbaren Vorteil körperlichen und psychischen Wohlbefindens, da die Ketonkörper sättigend (75-77) und leicht stimmungsaufhellend wirken.

Beim Lipödem scheint sich die ketogene Ernährung in Bezug auf Gewichtsreduktion und Beschwerdesymptomatik als besonders wirksam zu erweisen ( Abb. 5, - Abb. 6). Sie führt nicht nur zu Gewichtsverlust und Abbau des viszeralen Fetts sondern auch zu einer Reduktion des alimentären, also nicht ausschließlich durch das Lipödem bedingten subkutanen Fettgewebes an den Extremitäten. Nach eigenen Untersuchungen werden in über $80 \%$ der Fälle die typischen Beschwerden wie Spannungsgefühle, Ödemneigung, oft auch die Druckdolenz, gebessert, sodass häufig eine Reduktion der Therapiemaßnahmen möglich wird (50). Interessanterweise verspüren häufig auch normalgewichtige Patientinnen durch Vermeiden von raffinierten Kohlenhydraten und Zucker eine Linderung ihrer Beschwerden. Diese Beschwerdebesserung ist also nicht nur auf die Gewichtsreduktion, sondern sehr wahrscheinlich auf die antiinflammatorischen und antiödematösen Effekte der Stoffwechselumstellung zurückzuführen.

\section{Weitere Empfehlungen zur Ernährung}

Auch zuckerfreie Süßungsmittel sollten so selten wie möglich und nicht in größeren Mengen verzehrt werden, da sie über den Geschmackssinn ebenfalls die Insulinsekretion erhöhen können (sogennante „cephalic phase"), auch wenn sie keine verwertbaren Kohlenhydrate enthalten, so dass es anschließend zum Blutzuckerabfall kommt (78-80). Für einige Süßungsmittel wird zudem eine Schädigung der gesunden Darmflora diskutiert $(81,82)$. Eine Studie aus Basel fand hingegen für die Polyole Erythrol und Xylitol deutliche Vorteile. Sie zeigen nicht nur keine (Erythrol) oder nur geringe (Xylitol) Wirkung auf Plasmaglukose und Plasmainsulin, sondern wirken zudem sättigend, da sie die Magenentleerung verlangsamen und die Inkretion der sättigenden Hormone CCK und GLP-1 steigern (83).

Eine pathologisch veränderte Darmflora trägt über das Immunsystem zur Entwicklung von niedrigschwelliger Entzündung, Insulinresistenz und metabolischem Syndrom bei.

Zudem kann ein verändertes Mikrobiom die Energieaufnahme um 10 bis 15 Prozent erhöhen und so zur Adipositas beitragen (84). Zur Aufrechterhaltung einer gesunden Darmflora sollte die Ernährung deshalb vor allem reich an löslichen Ballaststoffen (Inulin, Oligofruktose, resistente Stärke, Pektin, mindestens 30g/Tag) und zuckerarm sein $(85,86)$.

\section{Fazit}

In verschiedenen Arbeiten konnte gezeigt werden, dass durch Gewichtsreduktion die Hautveränderungen bei der sekundären venösen Insuffizienz gebessert und die thrombogenen Risikofaktoren gesenkt werden können. Das Adipositas-assoziierte Lymphödem kann sich vollständig zurückbilden, die Symptomatik beim Lipödem deutlich zurückgehen. Neben der Behandlung der jeweiligen akuten oder chronischen Symptomatik durch Antikoagulation, Kompression, Lymphdrainage oder Wundtherapie müssen sich die therapeutischen Bemühungen darauf richten, durch Ernährungsumstellung und Lebensstilmodifikation das Gewicht, besonders die viszerale Adipositas, die Insulinresistenz und die damit einhergehenden proinflammatorischen, ödemverstärkenden und prokoagulatorischen Effekte des Fettgewebes nachhaltig zu reduzieren.

\section{Danksagung}

Ich danke sehr herzlich Frau Dr. Yvonne Frambach, die mir ihre hervorragenden Ausführungen zur Rolle der Inflammation beim Lymphödem für diesen Artikel zur Verfügung gestellt und diesen damit ganz wesentlich bereichert hat.
Interessenkonflikt

Nach Angaben der Autoren bestehen keine Interessenkonflikte.

\section{Ethische Richtlinien}

Für das Manuskript wurden keine Studien an Menschen oder Tieren durchgeführt.

\section{Literatur}

1. So dick war Deutschland noch nie. Ergebnisse des 13. DGE-Ernährungsberichts zur Übergewichtsentwicklung. Presseinformation: Presse, DGE aktuell, Februar 2017.

2. Benigni JP, Cazaubon M, Tourneroche A, AchhammerI, Mathieu M. Is obesity an aggravating factor in chronic venous disease? Results of a French epidemiological study in male patients. Int Angiol 2006; 25: 297-303.

3. Stunkard AJ, Sørensen TI, Hanis C et al. An adoption study of human obesity. N Engl J Med. 1986 Jan 23; 314(4): 193-8.

4. Stunkard AJ, Harris JR, Pedersen NL et al. The body mass index of twins who have been reared apart. N Engl J Med. 1990 May 24; 322 (21): 1483-7.

5. Schienkiewitz, Mensink GBM, Ronny Kuhnert, Lange C. Übergewicht und Adipositas bei Erwachsenen in Deutschland. Journal of Health Monitoring 2017 2(2) DOI 10.17886/RKI-GBE-2017-025 Robert Koch-Institut, Berlin

6. Cameron JD, Cyr MJ, Doucet E. Increased meal frequency does not promote greater weight loss in subjects who were prescribed an 8-week equienergetic energy-restricted diet. Br J Nutr. 2010 Apr; 103(8): 1098-1101.

7. Rosmond R, Dallmann MF, Björntorp P. Stress-related cortisol secretion in men: relationships with abdominal obesity and endocrine, metabolic and hemodynamic abnormalities. J Clin Endocrinol Metab 1998; 83(6): 1853-1859.

8. Watanabe M, Kikuchi H, Tanaka K et al. Association of Short Sleep Duration with Weight Gain and Obesity at 1-Year Follow-Up: A Large-Scale Prospective Study. Sleep 2010; 33(2):161-7. DOI.org/10.1093/sleep/33.2.161

9. Hasler G, Buysse J, Klaghofer R et al. The Association Between Short Sleep Duration and Obesity in Young Adults: a 13-Year Prospective Study. Sleep, 2004 Jun, 27(4): 661-666.

10. Cappucchio FP, Taggart FM, Kandala NB et al. Meta-Analysis of Short Sleep Duration and Obesity in Children and Adults. Sleep, 2008; 31(5): 319-326.

11. Faerber G. Der übergewichtige Patient mit CVI oder Lymphödem: Risikofaktor oder Ursache? Vasomed 2014; 26: 10-11. Bonner Venentage 2014.

12. Göstl K, Obermayer A, Hirschl M. Pathogenesis of chronic venous insufficiency by obesity. Current data and hypotheses. Phlebologie 2009; 38: 108-113.

13. Abdollahi M, Cushman M, Rosendaal FR. Obesity: risk of venous thrombosis and the interaction with 
coagulation factor levels and oral contraceptive use. Thromb Haemost 2003; 89: 493-498.

14. Ageno W, Piantanida E, Dentali F et al. Body mass index is associated with the development of the postthrombotic syndrome. Thromb Haemost 2003; 89: 305-309.

15. Chiesa R, Marone EM, Limonie C et al. Chronic venous disorders: correlation between visible signs, symptoms, and presence of functional disease. J Vasc Surg. 2007; 46: 322-330

16. Padberg F Jr, Cerveira JJ, Lal BK et al. Does severe venous insufficiency have a different etiology in the morbidly obese? Is it venous? J Vasc Surg 2003; 37: 79-85.

17. Vlajinac HD , Marinkovic JM, Maksimovic MZ et al. Body Mass Index and Primary Chronic Venous Disease - A Cross-sectional Study. European Journal of Vascular and Endovascular Surgery 2013; 45 (3): 293-298

18. Danielsson G, Eklof B, Grandinetti A, Kistner RL The influence of obesity on chronic venous disease. Vasc Endovascular Surg 2002; 36: 271-276.

19. Obermayer A, Göstl K, Walli G, Benesch T. Chronic venous leg ulcers benefit from surgery: long-term results from 173 legs. J Vasc Surg 2006; 44: 572-579.

20. Bjellerup M. Determining venous incompetence: a report from a specialised leg ulcer clinic. J Wound Care 2006; 15: 429-436.

21. Sugerman HJ, Sugerman EL, Wolfe L et al. Risks and benefits of gastric bypass in morbidly obese patients with severevenous stasis disease. Ann Surg 2001; 234: 41-46.

22. Benigni JP. Wirksamkeit von Gewichtsabnahme auf die Entwicklung chronisch venöser Insuffizienz nach operativer Magenverkleinerung bei übergewichtigen Patienten. 15. Bonner Venentage vom 27./28. Februar 2008. Vasomed 2009; 1: 26-27.

23. Garzon K, Obermayer A, Hirscher M. Das adipositasassoziierte Dependency-Sndrom. Vasomed 2010; 22(5): 218

24. Doerler M, Altmeyer P, Stücker M. Ulcus cruris venosum auf dem Boden eines Adipositas-assoziierten Dependency-Syndroms. Phlebologie 2013;42: 205-208.

25. Reich-Schupke, S. Die besondere Rolle der Adipositas in der Lymphologie.Vasomed 2014; 5 : $230-236$.

26. Flaggl F, Döller W, Jäger G et al. Prävalenz komorbider psychischer Störungen bei Lymphödempatienten in der medizinischen Rehabilitation. Praxis Klinische Verhaltensmedizin und Rehabilitation 2006; 7(1): 75-82.

27. Greene AK, Grant FD, Slavin SA. Lower-extremity lemphedema and elevated body-mass index. N Engl J Med 2012; 366: 2136-2137.

28. Shaw C, Mortimer P, Judd PA. A randomized controlled trial of weight reduction as a treatment for breast cancer- related lymphedema. Cancer 2007; 110: 1868-1874.

29. Reich-Schupke S. Compression therapy in obese patients Phlebologie 2015; 44: 71-76.

30. Schmeller W, Hüppe M, Meier-Vollrath I. Langzeitveränderungen nach Liposuktion bei Lipödem. LymphForsch 14 (2) 2010L: 17- 28.

31. Rapprich S, Loehnert M, Hagedorn M. Therapy of lipoedema syndrome by liposuction under tumes- cent local anaesthesia. Ann Dermatol Venereol 2002; 129: 1S711.

32. Herpertz U. Die häufigsten Beinödeme. Differenzierung zwischen Phlebödem, Lymphödem und Lipödem. Phebologie 2001; 30: 48-52.

33. Schmeller W, Meier-Vollrath I. Lipödem - Aktuelles zu einem weitgehend unbekannten Krankheitsbild. Akt Dermatol 2007; 33: 1-10.

34. Willenberg T, Schumacher A, Amann-Vesti B. Impact of obesity on venous hemodynamics of the lower limbs. J Vasc Surg 2010;52:664-8. https://doi.org/10.1016/j.jvs.2010.04.023

35. Darvall KA, Sam RC, Silverman SH et al. Obesity and thrombosis. Eur J Vasc Endovasc Surg 2007; 33: 223-233.

36. Ageno W, et al. Association between the metabolic syndrome, its individual components, and unprovoked venous thromboembolism. Arterioscler Thromb Vasc Biol 2014; 34: 2478-2485.

37. Juhan-Vague I, Vague P, Alessi MC et al. Relationships between plasma insulin triglyceride, body mass index, and plasminogen activator inhibitor 1 .

38. Juhan-Vague I, Roul C Alessi MC et al. Increased plasminogen activator inhibitor activity in non in sulin dependent diabetic patients - relationship with plasma insulin. Thromb Haemost 1989, 61: 370-373.

39. Karaman S, Hollmén M, Robciuc MR, et al. Blockade of VEGF-C and VEGF-D modulates adipose tissue inflammation and improves metabolic parameters under high-fat diet. Molecular Metabolism 2015; 4(2): 93-105.

40. Karaman S, Hollmén M, Yoon S-Y, et al. Transgenic overexpression of VEGF-C induces weight gain and insulin resistance in mice. Scientific Reports 2016; 6: 31566.

41. Harford K, Reynolds C, McGillicuddy F, Roche H. Fats, inflammation and insulin resistance: Insights to the role of macrophage and T-cell accumulation in adipose tissue. Proceedings of the Nutrition Society $2011 ; 70(4), 408-417$.

42. Gomez-Ambrosi J, Catalan V, Rodriguez A, Ramirez B, Silva C, Gil MJ Involvement of serum vascular endothelial growth factor family members in the development of obesity in mice and humans. Journal of Nutritional Biochemistry. 2010;21:774-780.

43. Silha J, Krsek M, Sucharda P, Murphy L. Angiogenic factors are elevated in overweight and obese individuals. International Journal of Obesity 2005; 29: $1308-1314$

44. Elias I, Franckhauser S, Ferré T, Vilà L Tafuro S, Muñoz S, Roca C, Ramos D, Pujol A, Riu E et al. Adipose tissue overexpression of vascular endothelial growth factor protects against diet-induced obesity and insulin resistance. Diabetes 2012; 61: 1801-1813.

45. Escobedo N, Oliver G The Lymphatic Vasculature: Its Role in Adipose Metabolism and Obesity. Cell Metabolism 2017; 26(4): 598-609.

46. Ogata, Fusa et al. Excess Lymphangiogenesis Cooperatively Induced by Macrophages and CD4+ T Cells Drives the Pathogenesis of Lymphedema Journal of Investigative Dermatology 2016; 136: 706-714.

47. Ly CL, Kataru RP, Mehrara BJ. Inflammatory Manifestations of Lymphedema. Jackson C, ed. International Journal of Molecular Sciences 2017; 18(1): 171 .
48. S1-Leitlinie Lipödem - AWMF: www.awmf.org/ leitlinien/detail/11/037-012.

49. Marshall M, Schwahn-Schreiber C. Das Lipödem - ein wenig beachtetes Krankheitsbild. Vasomed 2008; 20: 59-65.

50. Faerber G. Ernährungstherapie bei Lipödem und Adpositas - Ergebnisse eines leitliniengerechten Therapiekonzepts. Vasomed 2017; 29: 122-123.

51. Faerber G. Antiinflammatorische Ernährung, was ist das und was bringt sie uns beim Lipödem? Vasomed 2017; 29: 2-3. Vortrag, 59. Jahrestagung der Deutschen Gesellschaft für Phlebologie, Stuttgart 20.-23. September 2017.

52. Cohen PG. Aromatase, adiposity, aging and disease. The hypogonadal-metabolic-atherogenicdisease and aging connection. Med Hypotheses 2001; 56: 702-708.

53. Ivandić A, Prpić-Krizevac I, Sucić M et al. Hyperinsulinemia and sex hormones in healthy premenopausal women: Relative contribution of obesity, obesity type, and duration of obesity. Metabolism - Clinical and Experimental 1998; 47: 13-19.

54. Nestler JE, LINDA P. Powers LP, Matt DW et al. A Direct Effect of Hyperinsulinemia on Serum Sex Hormone-Binding Globulin Levels in Obese Women with the Polycystic Ovary Syndrome, The Journal of Clinical Endocrinology \& Metabolism, 1991; 72: 83-9.https://doi.org/ 10.1210/jcem-72-1-83.

55. Church TS, Blair SN, Cocreham S, Johannsen N, Johnson W, Kramer K, Mikus CR, Myers V, Nauta M, Rodarte RQ, Sparks L, Thompson A, Earnest CP. Effects of aerobic and resistance training on hemoglobin Alc levels in patients with type 2 diabetes: a randomized controlled trial. JAMA 2010; 304: 2253-2262

56. Feinman RD, Pogozelski WK, Astrup A et al. Dietary carbohydrate restriction as the first approach in diabetes management: Critical review and evidence base. Nutrition 2015; 31: 1-13. DOI: https://doi.org/10.1016/j.nut.2014.06.011

57. Mizushima N, Noda T,Yoshimori T et al. (1998). A protein conjugation system essential for autophagy. Nature 1998; 395: 395-398.

58. Harvie M, Wright C, Pegington $M$ et al. The effect of intermittent energy and carbohydrate restriction vs. daily energy restriction on weight loss and metabolic disease risk markers in overweight women. British Journal of Nutrition 2013; 110: 1534-1547. doi:10.1017/S0007114513000792

59. Klempel MC et al. Intermittent fasting combined with calorie restriction is effective for weight lossand cardio-protection in obese women. Nutr J 2012; 11: 98. Doi:10.1186/1475-2891-11-98

60. Lim EL, Hollingsworth KG et al. Reversal of type 2 diabetes: normalisation of beta cell function in association with decreased pancreas and liver triacylglycerol. Diabetologia 2011; 54: 2506-2514.

61. Steven S, Taylor R. Restoring hyperglycaemia by very low calorie diet in long and short duration type 2 diabetes. Diabet Med 2015; 32(9): 1149-1155.

62. Marsk R, Jonas E, Rasmussen F et al. Nationwide cohort study of post-gastric bypass hypoglycaemia including 5040 patients undergoing surgery for obesity in 1986-2006 in Sweden. Diabetologica 2010; 53: 2307-2311. 
63. Tindle HA, Omalu B, Courcoulas A et al. Risk of suicide after long-term follow-up from bariatric surgry. Am J Med 2010; 123: 1036-1042.

64. Conason A, Teixeira J, Hsu CH et al. Substance use following bariatric weight loss surgery. Arch Surg 2012; 1-6.

65. Ditschuneit HH, Flechtner-Mors M, Johnson TD, Adler G. Metabolic and weight-loss effects of a long-term dietary intervention in obese patients. Am J Clin Nutr 1999; 69(2): 198-204. http://www. ncbi.nlm.nih.gov/pubmed/9989680.

66. Yancy WS, Olsen MK, Guyton JR et al. A LowCarbohydrate, Ketogenic Diet versus a Low-Fat Diet To Treat Obesity and Hyperlipidemia: A Randomized, Controlled Trial. Ann Intern Med 2004; 140 769-777.

doi: 10.7326/0003-4819-140-10-200405180-00006

67. Westman EC, Feinman, RD, Mavropoulos, JC et al. Low-carbohydrate nutrition and metabolism. The American journal of clinical nutrition 2007; 86(2): 276-284.

68. Noakes T. Low-carbohydrate and high-fat intake can manage obesity and associated conditions: Occasional survey. South African Medical Journa 2013; 103(11): 826-830. doi:10.7196/SAMJ.7302

69. Maalouf M, Rho JM, Mattson MP. The neuroprotective properties of calorie restriction, the ketogenic diet, and ketone bodies. Brain research reviews 2009; 59(2): 293-315.

70. Stafstrom CE, Rho JM. The ketogenic diet as a treatment paradigm for diverse neurological disorders. Frontiers in pharmacology 2012; 3.

71. Youm YH, Nguyen KY, Grant RW. The ketone metabolite $\beta$-hydroxybutyrate blocks NLRP3 in flammasome-mediated inflammatory disease. $\mathrm{Na}$ - ture Medicine 2015; 21: 263-269. doi:10.1038/nm.3804.

72. Sofi F, Buccioni A, Cesari F et al. Effects of a dairy product (pecorino cheese) naturally rich in cis- 9, trans-11 conjugated linoleic acid on lipid, inflammatory and haemorheological variables: a dietary intervention study. Nutr Metab Cardiovasc Dis 2010; 20: 117-124. doi:10.1016/ j.numecd.2009.03.004.

73. Markova M, Pivovarova O, Hornemann S et al Isocaloric diets high in animal or plant protein reduce liver fat and inflammation in individuals with type 2 diabetes. Gastroenterology 2017; 152(3): 571-585. doi: 10.1053/j.gastro.2016.10.007.

74. Westerterp-Plantega MS, Lemmens S, Westerterp KR. Dietary protein - its role in satiety, energetics, weight loss and health. British Journal of Nutrition; Volume 108, Issue S2: 105-112 https://doi.org/10.1017/S0007114512002589

75. Paoli A, Bosco G, Camporesis EM et al. Ketosis, ketogenic diet and food intake control: a complex relationship. Front Psychol 2015; 6: 1-7. https://doi.org/10.3389/fpsyg.2015.00027

76. Sumithran P, Prendergast LA, Delbridge E eta al. Ketosis and appetite-mediating nutrients and hormones after weight loss. Eur J Clin Nutr 2013; 67: 759-764.

77. Johnstone AM, Horgan GW, Murison SD et al. Effects of a high-protein ketogenic diet on hunger, appetite, and weight loss in obese men feeding ad libitum. Am J Clin Nutr 2008; 87: 44-55.

78. Smeets PA et al. Functional magnetic resonance imaging of human hypothalamic responses to sweet taste and calories. Am J Nutr 2005; 82(5): 1001-1006.
79. Just T, Pau HW, Engel U et al. Cephalic phase insulin release in healthy humans after taste stimulation? Appetite 2008; 51; 622-627.

80. Pepino MY et al. Sucralose affects glycemic and hormonal responses to an oral glucose load. Diabetes Care 2013; 36(9): 2530-2535.

81. Abou-Donia M, El-Masry E, Abdel-Rahman A et al. Splenda alters gut microflora and increases intestinal P- glycoprotein and cytochrome P-450 in male rats. Journal of Toxicology and Environmental Health 2008; 71: 1415-1421.

82. Suez J, Korem T, Zeevi D, Zilberman-Schapira G, Artificial sweeteners induce glucose intolerance by altering the gut microbiota. Nature 2014; 514: 181-186.

83. Wölnerhanssen B, Cajacob L, Keller N et al. Gut hormone secretion, gastric emptying, and glycemic responses to erythritol and xylitol in lean and obese subjects. Am J Physiol Endocrinol Metab 2016; 310: E1053-E1061. doi:10.1152/ajpendo.00037.2016.

84. Turnbaugh PG et al. An obesity-associated gut microbiome with increased capacity for energy harvest. Nature 2006; 444: 1027-1031.

85. Dibaise JK et al. Gut Microbiota and Its Possible Relationship With Obesity. Mayo Clinic Proceedings 2008; 83: 460-469.

86. Duncan SH et al. Reduced dietary intake of carbohydrates by obese subjects results in decreased concentrations of butyrate and butyrate-producing bacteria in feces. Applied and Environmental Microbiology 2007; 73: 1073-1078. 